\title{
The Impact of Covid-19 on Community-Based Violence Interventions
}

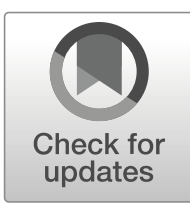

Irshad Altheimer ${ }^{1}$ • Janelle Duda-Banwar ${ }^{1}$ • Christopher J. Schreck ${ }^{2}$ (D)

Received: 12 June 2020 / Accepted: 12 June 2020 /

Published online: 19 June 2020

(C) Southern Criminal Justice Association 2020

\begin{abstract}
This paper examines the impact of Covid-19 on community-based violence interventions, especially hospital-based violence interventions and street outreach organizations. Guided by our work in Rochester, New York, we explore how the emergence of covid-19, and the subsequent social restrictions, have hampered the ability of community-based organizations to respond to violence. We also examine ways that community-based organizations can adapt to the challenges associated with Covid-19 and continue providing services to the community.
\end{abstract}

Keywords Covid 19 . Violence reduction - Street outreach · Hospital-based violence interventions $\cdot$ Violence victimization

\section{Introduction}

COVID-19 has placed a considerable burden on our public health system. Presently, more than 89,000 people in the United States have died and another 1.4 million have been infected (see https://www.cdc.gov/coronavirus/2019-ncov/cases-updates/cases-inus.html). ${ }^{1}$ In places where COVID-19 is most prevalent, caring for the infected has had a substantial impact on the ability of the health care system to provide quality care. For instance, according to the Institute for Health Metrics Evaluation, on April 9, 2020, when the current wave of the pandemic peaked in New York state, there was a projected statewide shortage of 7036 hospital beds, including a shortage of 5534

${ }^{1}$ Due to the limited availability of testing, the actual number of infected persons is likely much higher. For instance, Lin et al. (2020) found that $86 \%$ of COVID-19 cases in China during the early stages of the pandemic went undetected.

Irshad Altheimer

ixagcj@rit.edu

1 Department of Criminal Justice, Center for Public Safety Initiatives, Rochester Institute of Technology, Rochester, NY, USA

2 Department of Criminal Justice, Rochester Institute of Technology, Rochester, NY, USA 
intensive care units (see https://covid19.healthdata.org/united-states-of-america). Such shortages can prove potentially deadly for patients seeking acute care for COVID-19 infections, but also make it difficult for hospitals to provide effective treatment to patients seeking assistance for non COVID-19 related ailments, including victims of violence.

Community-based organizations such as hospitals play a unique role in responding to violence. Many hospitals in urban areas operate violence intervention programs that seek to provide services to violence victims in hopes of reducing revictimization and retaliation. These programs may operate on a stand-alone basis, or also include collaborations with community-based street outreach teams that provide mediation between disputants and change sub-cultural norms on violence. Both operate under a public health model that views violence as a contagion that should be treated like as disease (Slutkin, 2012) and involve direct provision of face-to-face support to violence victims.

Societal restrictions imposed due to COVID-19 have posed challenges for violence street outreach workers. On one hand, intense face-to-face interaction with their clients places them at direct risk of COVID-19 infection. On the other hand, societal restrictions imposed in response to COVID-19 may make it nearly impossible for them to carry out work-related tasks. Further, it is unlikely that many of the non-profit organizations through which street outreach workers operate have the resources to provide support for sophisticated video conferencing technology. ${ }^{2}$ The conflict between job requirements and the necessity of social distancing contributes to higher stress levels among street outreach workers.

In spite of challenges posed to program staff and outreach workers by the COVID-19 pandemic, there is reason to believe that violence persists and the work of prevention professional is needed during the pandemic. Criminologists have just begun to explore the impact of COVID-19 and related social restriction policies on violence. One early study suggested that COVID-19 may reduce levels of violence (McDonald \& Balkin, 2020), but newly emerging research suggests otherwise (Campedelli, Aziani, \& Favarin, 2020; Mohler et al., 2020). Violence continues unabated in Rochester, NY. From March 12, 2020, when the first case of COVID-19 was identified in Monroe County, to May 3, 2020, there were 6 homicides and 28 non-fatal shootings in the city of Rochester. In the month of April alone, there were 20 shootings (both fatal and non-fatal) involving 25 victims. Over the previous 3 years (2017 to 2019) the average number of shooting victims in the month of April was 14. The violence in April suggests that the New York stay at home order imposed on March 20, 2020 has not impacted violent offenders. It appears that neither the presence of the virus nor the imposition of government mandated social restrictions has slowed violence in Rochester. Thus, the need for street outreach is ever present.

The emergence of COVID-19 and subsequent social restrictions has opened up new vistas for criminologists to explore. Of particular interest for this paper is the impact

\footnotetext{
${ }^{2} \mathrm{https}: / / w w w . w b e z . o r g / s t o r i e s / a n t i-v i o l e n c e-g r o u p s-l o b b y-f o r-20 m-i n-f e d e r a l-f u n d s / 8 f 8 b c 492-e 97 f-43 e c-81$ f8-28a2624d6975?utm_source $=$ The $\% 20$ Marshall\%20Project $\% 20$ Newsletter\&utm_campaign $=23 \mathrm{c} 7636 \mathrm{c} 20$ EMAIL_CAMPAIGN_2020_04_28_11_49\&utm_medium $=e m a i l \& u t m \_t e r m=0 \_\overline{5 e} 02 \mathrm{cdad} 9 \mathrm{~d}-23 \mathrm{c} 7636 \mathrm{c} 20$ 174376333
} 
that COVID-19 has had on community-based violence reduction strategies. The objective of this paper is to examine the impact of COVID-19 on hospital based-violence interventions and street outreach programs. Toward that end, we seek to address the following research questions:

1. How has COVID-19 impacted community-based responses to violence?

2. In what ways can community-based organizations adapt to the challenges associated with Covid-19?

\section{Overview of COVID-19 Effects on Outreach}

The emergence of COVID-19 has led to many restrictions on social life. No national social restrictions are in place, and the exact features of the restrictions vary by state, but currently every state in the union has declared an emergency in response to COVID-19 and enacted state-specific restrictions. ${ }^{3}$ The exact features of the restrictions most often involve some aspect of the following:

1. Social distancing

2. Statewide school closures

3. Closing of businesses

4. Limitations on travel

5. Face covering requirements

6. National Guard Deployments

In addition to the statewide regulations, the national Centers for Disease Control and Prevention (or CDC) has provided guidelines to hospitals that have direct implications for the ability of prevention professionals operate effectively when in a hospital setting. ${ }^{4}$ Most important for the purpose of this paper are CDC's limits on visitors. For example, the CDC recommends limiting visitation only to those who are essential for the patient's physical or emotional well-being and care and encouraging the use of alternative mechanisms for patient and visitor interactions such as video-call applications on cell phones or tablets. While a favorable reading of the recommendations might lead one to assume that these recommendations would not inhibit prevention professionals from visiting violence victims in the hospital, the practical reality in Rochester suggests otherwise. At least one local hospital has prohibited prevention professionals from visiting violence victims in an attempt to stem the spread of COVID-19. Taken together, the limitations discussed above pose challenges for the ability of prevention professionals to carry out their tasks. The implications of these restrictions on community-based responses to violence will be discussed in more detail below.

\footnotetext{
${ }^{3}$ See https://www.ncsl.org/research/health/state-action-on-coronavirus-covid-19.aspx\#SA and https://www. nga.org/coronavirus/\#states

${ }^{4}$ https://www.cdc.gov/coronavirus/2019-ncov/hcp/infection-control-recommendations.html
} 


\section{Prevention Professionals, Street Outreach Workers and COVID-19}

A number of community-based violence reduction programs incorporate a hospitalbased component, with prevention professionals responding to hospitals when someone is shot or stabbed (Fischer, Cooper, Marks, \& Slutkin, 2020). These are frequently referred to as "Hospital-based violence intervention programs," or HVIPs. With hospitals rightly prioritizing their COVID-19 response, there is substantially reduced time and resources to link potential participants to these programs. For instance, hospitals risk reverting to the, "treat 'em and street 'em" approach (Zun, Downey, \& Rosen, 2003) or "pivot to triage", which effectively would amount to an elimination of HVIPs. As a result, consents, risk assessments, and service linkages would shift to postdischarge, increasing the exposure of patients to retaliation. Stay-at-home and social distancing orders preclude prevention professionals from appearing at the bedside of shooting and stabbing victims and building rapport. That vulnerable moment when these workers can connect with family, friends, and victims is now lost. Instead, prevention professionals must monitor news feeds, radio frequencies, and social media to find out that someone has been shot or stabbed. Further, they must wait for the consent process to unfold, which will likely be inconsistent at best with temporary healthcare staff and new priorities taking over in response to the pandemic. Without this crucial initial step of victims agreeing to participate in the intervention, hospital staff cannot connect victims to these community-based agencies.

Street outreach is a common component of community-based violence reduction efforts (Petrosino et al., 2015), with workers targeting individuals at high risk of engaging in violence. Outreach workers meet individuals in their assigned communities, spending significant time building these relationships, and shooting responses often involve door-to-door canvasing and community-walks. From our study of street outreach for over a decade, we know that outreach workers spend a significant amount of time in direct contact activity such as walking in neighborhoods, attending vigils and funerals, and transporting individuals across the community (e.g., Duda \& Klofas, 2013; Klofas, Duda, Schreck, \& Robertson, 2013). Workers' responsibilities frequently include connecting individuals with various programs and social services (Braga, Pierce, McDevitt, Bond, \& Cronin, 2008; Petrosino et al., 2015), providing case management (Engel, Tillyer, \& Corsaro, 2013), changing community norms through responding to every shooting and spreading positive cultural values (Picard-Fritsche \& Cerniglia, 2013).

Some community-based violence reduction models also utilize street outreach workers to mediate gang conflict (e.g., Webster, Whitehill, Vernick, \& Curriero, 2013; Wilson \& Chermak, 2011). Dispute mediation frequently occurs face to face, whether it is both parties coming together or outreach workers directly meeting with the parties separately to reach an agreement. Many such efforts include a storefront intended to serve as a safe place for participants to settle into and hang out temporarily, attracting them with amenities like video games, computers, and snacks.

With the introduction of COVID-19, these approaches are now considered a public health risk and are infeasible under the conditions of social distancing, isolation, and quarantining. The inability to meet in person creates profound challenges for effective outreach. Relationship-building must adapt to the current state; this might include being more adept to all the virtual ways that people interact. Some of the old standbys remain 
(phone calls, text messaging, and Facebook), but this also creates an opportunity for modified, creative approaches such as chatting through gaming (e.g., Twitch, Mixer) and video posting (e.g., TikTok). Outreach workers may shift to providing face masks (e.g., at vigils and funerals) and food as a way to build relationships. Service connection may transition to assisting participants with getting the required hardware and software for virtual appointments, along with frequent check-ins to encourage individuals to find alternative ways to handle disputes. Outreach workers may find themselves in a position of emotional and informational support during this time.

Challenges abound with this shift. In this new era distinguishing between essential and nonessential services, it is not clear where street outreach workers fit. Essential workers have taken on additional roles and that would become true for outreach workers. For example, outreach workers have a critical task of spreading accurate information regarding COVID-19, current executive orders, and effective protective measures to their community. They also need access to sanitizers, gloves, and face masks. Funding for community and grassroots organizations is an ongoing challenge, yet all these new measures cost money. There are challenges with innovation as well. Technology upgrades may be required to stream certain content and increases in bandwidth may be too costly. For example, these agencies now need internet that supports video streaming and file exchange relevant to their staff size in addition to new software and software licensing costs. Not fully understanding the technology platforms can cause some very real problems, such as the potential for confidential information to leak or misinterpreting messages and chat content. Many outreach workers do not have a high school education, which can exacerbate these challenges.

In addition, workers themselves may be under increased health-related stress, especially as particularly troubling data reveals a disproportionate impact of COVID-19 on the African-American community (Thebault, Ba Tran, \& Williams, 2020; Yancy, 2020). The data indicate not only higher infection and death rates from COVID-19, but also a disparate economic impact on the black community (Aratani \& Rushe, 2020). This poor outlook, compounded with issues around healthcare access, caregiver role, housing conditions, amongst a litany of other stressors, requires a dynamic response plan that anticipates and mitigates these difficulties faced by violence prevention outreach workers.

The circumstances created by COVID-19 do offer an opportunity for violence prevention outreach programs to pivot and focus on what works. For example, are there ways to seize on the vulnerable moment of being shot or stabbed that do not include hospital access or face-to-face interaction? What innovative strategies might emerge that provide new entry points for engaging participants? The ability to address these questions will support the development of new approaches that help organizations overcome the challenges associated with this pandemic and that may enhance the ability of community-based organizations to innovative solutions to violence going forward.

\section{Effects of COVID-19 on Hospital-Based Data and Tracking}

Tracking data in violence outreach work and hospitals has always been challenging. While hospital patient data tends to be sophisticated, there are significant limitations in terms of volume, searchability, and documentation. Further, hospitals do not conceptualize shootings in the same way that prevention professionals and outreach workers do; hospitals are concerned with coding data specific to injury type like organ damage, 
bleeding, broken bones, while outreach workers simply want to track that a shooting or stabbing victim arrived at the hospital. Tracking data for this population was challenging pre-pandemic, with no systematic mechanism to pull all the "shooting victims" that arrived at a hospital. With hospitals preparing for a surge of COVID-19 patients, any patient data tracking that did not have infrastructure in place pre-pandemic will likely cease to exist. Without such data, no intervention can take place in the hospital; instead, the onus shifts to prevention professionals and outreach workers to track shootings and respond via text, phone call, or other creative means in an attempt to engage potential participants. With skeleton teams likely to be running the intervention, there may be an increase in missed connections, no time or resources to make the link with the victim, and quality improvement staff shifting their focus to COVID-19. However, for those cases where consent is obtained, with so much work occurring electronically, an opportunity arises to use the digital footprint for tracking purposes. New apps or programs can be utilized to track the outreach work. For example, text apps like WhatsApp for messaging, and calendar apps for appointments (e.g., Outlook, Google calendar) automatically track the intervention. Efforts to track the bare minimum will be crucial to assessing program impact.

\section{The Rochester Case Study}

To elucidate the unique challenges that COVID-19 presents to community-based violence interventions, we explore the impact of COVID-19 on one communitybased violence prevention program in Rochester, NY. The program, known as Community Engagement to Reduce Victimization (CERV), is a collaborative effort between Rochester General Hospital (RGH) and three street-outreach organizations based in Rochester (Pathways to Peace, ABC Save Our Youth, and Rise Up Rochester). The program began in June 2019 and is funded by the New York State Health Foundation. It aims to reduce victimization by enhancing the existing HVIP at RGH and supporting collaboration between the organizations providing street outreach.

CERV has 5 core elements:

1. Designating a full-time CERV Coordinator to coordinate the activities of the partner organizations.

2. Utilizing a risk-assessment tool to identify the cases with a high risk of revictimization or retaliation.

3. Establishing a clear protocol to ensure a smooth hand-off from the hospital to the community.

4. Working with community partners to tailor a person-centered, trauma-informed response for the victim and their surrogates (friends, family, etc.)

5. Providing wrap-around services to reduce the likelihood of revictimization and retaliation.

The brief case illustration below demonstrates what an average case might look like:

A gunshot victim is brought to Rochester General Hospital in a private vehicle. He undergoes an intake screening and consents to be a part of CERV. A 
prevention professional from Pathways to Peace then performs a risk assessment and forwards it to the project coordinator. Upon reviewing the risk assessment, the project coordinator convenes a survivor intervention team meeting with the community partners and develops an action plan that outlines the next steps to be taken to reduce revictimization and retaliation. The action plan involves moving the victim to a hotel in Syracuse for 3 days while the dispute cools. The project coordinator arranges for travel for the victim and provides him with a $\$ 100 \mathrm{gift}$ certificate to pay for food and toiletries. During that time, an outreach worker from Save Our Youth connects the victim to wrap-around services and community referrals and attempts mediation between the disputants. The mediation occurs and the dispute is quashed, ending the risk of subsequent victimization at the moment. Subsequently, the victim is contacted and requested to perform a customer journey map to evaluate any gaps in the project and examine how participation in the project impacted outcomes for the victim.

COVID-19 has profoundly impacted CERV and reduced the capacity of community organizations to reduce violence. The following changes have occurred with the HVIP with our partner hospital. First, as a result of COVID-19, RGH has changed the consent process. Originally, clinicians would encourage violence victims to participate in the program and seek consent to call Pathways to Peace to perform a risk assessment while an in-patient the hospital. Now, a clinician gives the victim a card with contact information to Pathways to Peace and encourages the victim to call upon discharge. Second, as a precautionary measure to prevent the spread of COVID-19, RGH has barred prevention professionals from entering the hospital from engaging violence victims and their surrogates. These changes have reduced consent levels among violence victims and disrupted the ability of prevention professionals to follow, identify, and track violence victims into the community.

In addition to the impact on the hospital, COVID-19 has impaired street outreach organizations in several ways. First, the project coordinator has been unable to convene in-person meetings in the community with partners from street outreach organizations in Rochester. Instead, all of the meetings have been held via video conferencing. Second, all of the community partners have faced unique challenges that have disrupted their ability to provide services to violence victims. One of the partner organizations has had to divert some of their time to other tasks, including handing out food at local emergency food pantries. Another community partner has been unable to engage participants due the lack of PPE. A third partner organization has been limited in their ability to respond because many volunteers are unable or unwilling to participate while COVID-19 restrictions are in place. Third, all of the community partners have struggled to provide wrap-around services and engage violence victims while practicing social distancing. Fourth, these restrictions have also made it difficult to interview participants about how they have been impacted by the program.

The limitations noted above impact the ability of street outreach workers to establish rapport with violence victims and build the trust that is critical for this type of work (Whitehill, Webster, Frattaroli, \& Parker, 2014). Standard trust building practices for this hard-to-reach population, such as sharing a meal and providing transportation, are no longer an option. Local prevention professionals have been unable to make a personal connection with the violence victims immediately after their victimization 
and this has undermined the ability of prevention professionals to provide case management and dispute mediations. This has also inhibited the ability of local outreach workers to engage active disputants in attempt to manage the situation and enforce a cool down period early on in the dispute.

The challenges noted above have serious implications for the ability of communitybased organizations to track and monitor violence victimization. We are just beginning to understand the implications of COVID-19. Thus far, we have identified violence victims who were located by street outreach workers yet who were omitted in hospital data. Further, to date, none of the violence victims that received Pathways to Peace contact information at the RGH emergency room have called to request services. Additionally, local outreach workers have had difficulty collecting the street intelligence that is vital to interrupting violence before it occurs.

The ongoing violence has also led to intense discussions concerning the proper way for the community to grieve with social distancing guidelines in effect. Community leaders have had to acknowledge the very human need to come together and grieve someone's death, while facing the reality that dense public gatherings are how covid-19 spreads rapidly. In one instance, there was public outcry, and a subsequent backlash, when 200 Rochestarians gathered at a vigil to commemorate the life of a young man who was recently murdered. ${ }^{5}$ The question that outreach workers now face is how to deal with community trauma while not placing themselves or members of the community at risk of COVID-19.

\section{Conclusion}

COVID-19 has led to unprecedented challenges for community-based violence interventions. These challenges will require innovative responses that equip outreach workers with the tools they need to respond to violence while protecting themselves and following social distancing guidelines. The continuation of violence in urban communities requires a sense of urgency to both provide services for victims and maintain the momentum that existing outreach programs have attained in the community.

Efforts must be taken to enhance the ability of outreach workers to connect with victims of violence. This may require providing victims with the technological tools they need to connect to outreach workers, or finding innovative ways to meet in spaces where confidentiality and social distancing can be maintained. It also requires thinking of new ways to gather street intelligence that is so vital to this work.

This intervention also provides an opportunity for community-based organizations to reassess what success looks like in the current environment. Are there ways to incentivize online connections between violence victims and outreach workers? What does effective trauma informed care look like if it is not done in person? Can wrap-around services be virtual? Our ability to answer such questions going forward will impact how well community-based interventions prevent violence in the COVID-19 era.

\footnotetext{
${ }^{5}$ See https://13wham.com/news/local/warren-speaks-out-after-weekend-violence-we-can-be-better; and https://www.democratandchronicle.com/story/news/2020/04/17/race-fault-lines-social-distancing-rochesterny-coronavirus/2984471001/
} 


\section{References}

Aratani, L. \& Rushe, D. (2020). African Americans bear the brunt of Covid-19's economic impact. The Guardian. Retrieved from, https://www.theguardian.com/us-news/2020/apr/28/african-americansunemployment-covid-19-economic-impact

Braga, A. A., Pierce, G. L., McDevitt, J., Bond, B. J., \& Cronin, S. (2008). The strategic prevention of gun violence among gang-involved offenders. Justice Quarterly, 25(1), 132-162.

Campedelli, G.M., Aziani, A. Favarin, S. 2020. Exploring the effect of 2019-nCoV containment policies on crime: The case of Los Angeles. Available at https://doi.org/10.31219/osf.io/gcpq8.

Duda, J. \& Klofas, J. (2013). Rochester youth violence partnership final report. Center for Public Safety Initiatives at Rochester Institute of Technology. Funded by New York State Division of Criminal Justice Services.

Engel, R. S., Tillyer, M. S., \& Corsaro, N. (2013). Reducing gang violence using focused deterrence: Evaluating the Cincinnati initiative to reduce violence (CIRV). Justice Quarterly, 30(3), 403-439.

Fischer, K. R., Cooper, C., Marks, A., \& Slutkin, G. (2020). Prevention professional for violence intervention: A newly recognized health care provider for population health programs. Journal of Health Care for the Poor and Underserved, 31(1), 25-34.

Klofas, J., Duda, J., Schreck, C. J., \& Robertson, O.N. (2013). SNUG evaluation. Center for Public Safety Initiatives at Rochester Institute of Technology. Funded by New York State Division of Criminal Justice Services.

Lin, R., Pei, S., Chen, B., Song, Y., Zhang, T., Yang, W., \& Shaman, J. (2020). Substantial undocumented infection facilitates the rapid dissemination of novel coronavirus (SARS-CoV2). Science. https://doi. org/10.1126/science.abb3221.

McDonald, J.F. and Balkin, S. The COVID-19 and the Decline in Crime. (April 2, 2020). Available at SSRN: https://ssrn.com/abstract=3567500 or https://doi.org/10.2139/ssrn.3567500

Mohler, G., Bertozzi, A., Carter, J., Short, M.B. Sledge, D. Tita, G. Uchida, C. G., Brantingham, P. J. (2020). Impact of social distancing during COVID-19 pandemic on crime in Los Angeles and Indianapolis. Forthcoming. Journal of Criminal Justice. https://www.researchgate.net/publication/340414800_Impact of_social_distancing_during_COVID-19_pandemic_on_crime_in_Indianapolis

Petrosino, A., Campie, P., Pace, J., Fronius, T., Guckenburg, S., Wiatrowski, M., \& Rivera, L. (2015). Crosssector, multi-agency interventions to address urban youth firearms violence: A rapid evidence assessment. Aggression and Violent Behavior, 22, 87-96. https://doi.org/10.1016/j.avb.2015.04.001.

Picard-Fritsche, S., \& Cerniglia, L. (2013). Testing a public health approach to gun violence: An evaluation of Crown Heights save our streets, a replication of the cure violence model. New York, NY: Center for Court Innovation https:/www.washingtonpost.com/nation/2020/04/07/coronavirus-is-infecting-killingblack-americans-an-alarmingly-high-rate-post-analysis-shows/?arc404=true.

Slutkin, G. 2012. Violence is a contagious disease. In Contagion of violence workshop summary. (1-18). Institute of Medical Health and National Research Council. https://doi.org/10.17226/13489

Thebault, R., Ba Tran, A., \& Williams, V. (2020, April 7). The coronavirus is infecting and killing black Americans at an alarmingly high rate. Washington Post. https://www.washingtonpost.com/nation/2020 /04/07/coronavirus-is-infecting-killing-black-americans-an-alarmingly-high-rate-post-analysisshows/?arc404=true

Webster, D. W., Whitehill, J. M., Vernick, J. S., \& Curriero, F. C. (2013). Effects of Baltimore's safe streets program on gun violence: A replication of Chicago's CeaseFire program. Journal of Urban Health, 90(1), 27-40.

Whitehill, J. M., Webster, D. W., Frattaroli, S., \& Parker, E. M. (2014). Interrupting violence: How the CeaseFire program prevents imminent gun violence through conflict mediation. Journal of Urban Health, 91(1), 84-95.

Wilson, J. M., \& Chermak, S. (2011). Community-driven violence reduction programs: Examining Pittsburgh's one vision one life. Criminology \& Public Policy, 10(4), 993-1027.

Yancy, C. (2020). COVID-19 and African Americans. JAMA, https://jamanetwork. com/journals/jama/fullarticle/2764789.

Zun, L. S., Downey, L. V., \& Rosen, J. (2003). Violence prevention in the ED: Linkage of the ED to a social service agency. The American Journal of Emergency Medicine, 21(6), 454-457.

Publisher's Note Springer Nature remains neutral with regard to jurisdictional claims in published maps and institutional affiliations. 
Irshad Altheimer is an Associate Professor of Criminal justice and the Director of the Center for the Public Safety Initiatives (CPSI) at RIT. He received his Ph.D. in sociology from Washington State University. Dr. Altheimer is actively engaged in scholarly research and has published articles in a variety of journals. His current research interests include dispute-related violence, retaliatory urban violence, and community-based violence reduction strategies. He has extensive experience working as a research partner with local law enforcement agencies addressing urban violence. Dr. Altheimer is currently serving as the principal investigator of a New York State Health Foundation grant that seeks to enhance community-based responses to violence in the City of Rochester, NY. He was awarded the 2014 W.E.B Dubois Fellowship by the National Institute of Justice.

Dr. Janelle Duda-Banwar is a Visiting Assistant Professor in the Department of Criminal Justice and a Senior Research Associate at the Center for Public Safety Initiatives (CPSI) at Rochester Institute of Technology. Duda-Banwar received her PhD in Social Welfare from Case Western Reserve University's Jack, Joseph, and Morton Mandel School of Applied Social Sciences. She received her MSW from California State University, Long Beach and her BSW from Xavier University in Cincinnati. Her research interests include court practices and justice, gun violence reduction, community responses to social problems, and moral and ethical development. Through CPSI she has worked closely with local agencies to develop, implement, and evaluate communitylevelinterventions. In this capacity, she has worked on projects to reduce gun violence, reduce recidivism, and to respond to emerging needs within the criminal justice system.

Christopher J. Schreck is Professor and Chair of the Department of Criminal Justice at the Rochester Institute of Technology. His work centers on understanding and explaning criminal victimization. He is a past editor of the Journal of Criminal Justice Education and the Journal of Crime and Justice. 